\title{
Haemorrhagic pericardial effusion in adult Gaucher's disease
}

\author{
G. T. Davies ${ }^{1}$ and H. M. Foreman \\ From Sully Hospital (Thoracic Centre), Penarth, Glamorgan
}

A case of adult Gaucher's disease presenting with haemorrhagic pericardial effusion is reported. Three similar cases have been reported. The possible aetiological factors in this case are assessed, the likely cause being thrombocytopenia due to hypersplenism associated with Gaucher's disease.

In 1882, Ernest Gaucher first described the disorder since known by his name. Hsia, Naylor, and Bigler (1959) found published reports of more than 300 cases, and there have been many further cases reported since. Most reports comment on the bleeding tendency associated with Gaucher's disease, attributing this to thrombocytopenia, but make the point that it is rare for major haemorrhage to occur (Reich, Seife, and Kessler, I95I; Strickland, I958).

Brill, Mandlebaum, and Libman (1905) and Welt, Rosenthal, and Oppenheimer (1929), each record a case of bloody effusion in the pericardial space in Gaucher's disease. Rosenfeld and Epstein (196I) describe a case of Gaucher's disease with haemorrhagic pericardial effusion but in which carcinoma cells were found on examination of the aspirated pericardial fluid. Roberts and Fredrickson (1967) describe a case with Gaucher's disease of the lungs causing severe pulmonary hypertension, acute recurrent pericarditis, and finally haemorrhagic cardiac tamponade. Zlotnick and Groen (I96I) describe a case of Gaucher's disease with extensive pericardial calcification which may have been due to organized haemopericardium. Benbassat et al. (1968) record a patient with Gaucher's disease and constrictive pericarditis, possibly resulting from haemorrhage into the pericardium. Because of the rarity of the presentation, in an uncommon disease, a fourth proven case of haemorrhagic pericardial effusion due to the bleeding diathesis of Gaucher's disease is reported.

\section{Case report}

History The patient was born in 1914 and was not aware of Jewish ancestry. He was known to

${ }^{1}$ Present address: Department of Radiodiagnosis, Royal Infirmary, Newport Road, Cardiff. have had adult Gaucher's disease since 1948 when he was investigated at the Middlesex Hospital, and had been troubled by various complications of this disease for some years - recurrent splenic pain, recurrent epistaxes and melaena, and aseptic necrosis of his left femoral head requiring operative treatment. He had been treated for pulmonary tuberculosis in 1935 and again in 1958-59, and had been observed regularly thereafter at a chest clinic (Fig. I).

Six weeks before his admission on this occasion he had noticed aching pain in the left side of his chest radiating to the right shoulder; the pain was persistent and disturbed his sleep. He became increasingly breathless on exertion. He had a paroxysmal cough, bouts of which made him feel faint. Because of these symptoms he was seen at the chest clinic, from whence he was admitted to Sully Hospital in June 1962.

Examination The patient had the typical pigmentation, pingueculae, hepatosplenomegaly, and other stigmata of Gaucher's disease. The jugular venous pulse was raised, the pulse wave was paradoxical in type. Cardiac dullness was increased and there was a protodiastolic triple rhythm on auscultation.

Investigations Chest $x$-ray showed gross cardiomegaly, suggesting pericardial effusion, and a small tuberculoma in the apical segment of the right upper lobe (Fig. 2). The electrocardiogram suggested pericarditis. Cardiac catheterization confirmed a large pericardial effusion (Fig. 3). Haematology showed a moderate pancytopenia: platelet count less than $100,000 / \mathrm{cu} . \mathrm{mm}$. on numerous occasions. Coagulation studies showed the only abnormality to be a reduced platelet count. Serum acid phosphatase, 8 units (normal I-3 units). Liver function tests normal. Viral agglutination titres were raised for influenza $A$ and psittacosis suggesting previous infections. Faecal occult blood was occasionally positive. Culture of gastric juice showed no acid-fast bacilli on 14 occasions. 


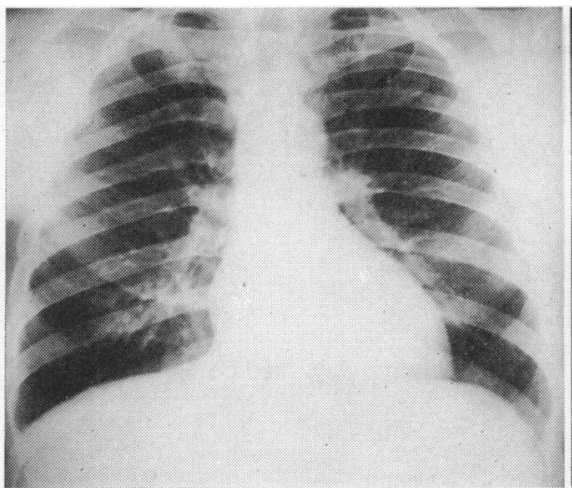

FIG. I

FIG. I Postero-anterior chest $\mathrm{x}$-ray, showing normal cardiac contour four years before admission.

FIG. 2 Postero-anterior chest $\mathrm{x}$-ray showing massive pericardial effusion on admission.

FIG. 3 Antero-posterior chest x-ray with right atrial injection of contrast medium, showing size of pericardial effusion.

FIG. 4 Postero-anterior chest $\mathrm{x}$-ray showing appearances after aspiration of pericardial effusion, with air replacement of the fluid.

FIG. 5 Postero-anterior chest $\mathrm{x}$-ray showing normal cardiac contour 18 months after discharge.

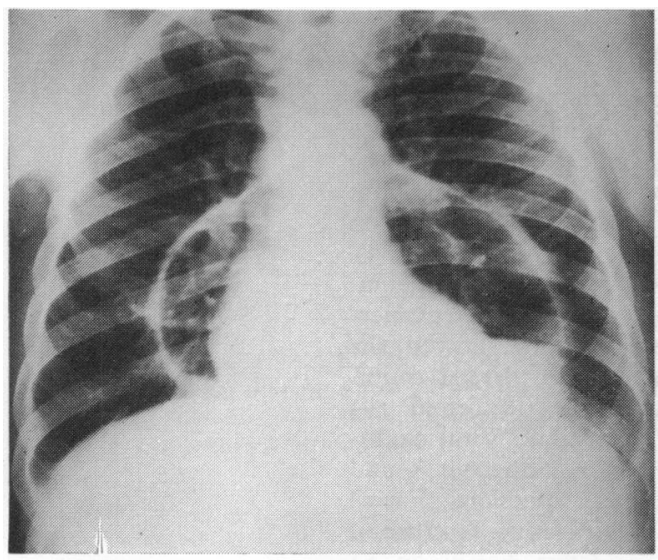

FI G. 4
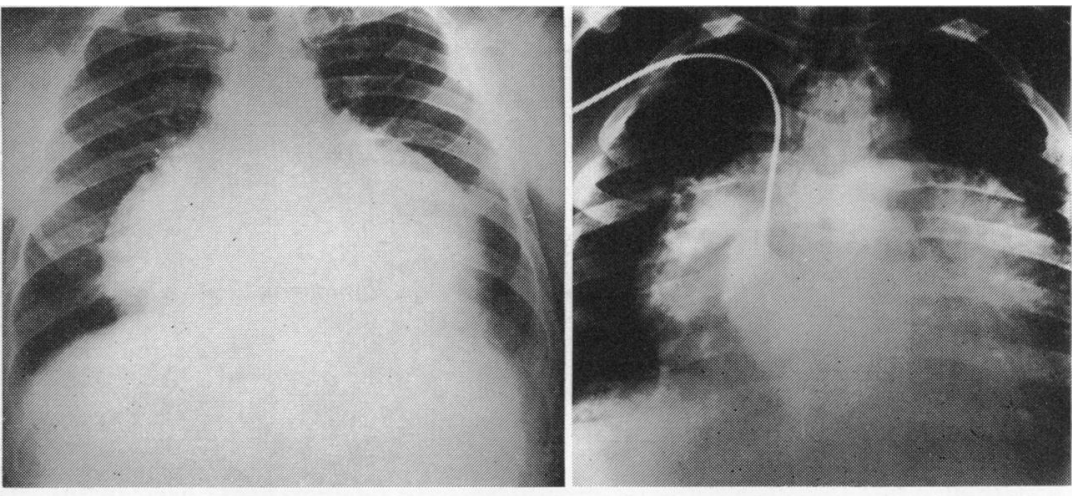

FIG. 2

FIG. 3

Treatment and progress Aspiration of the pericardial effusion was carried out on several occasions, the total amount of fluid aspirated being 2.75 litres. The fluid aspirated was heavily blood stained though not with fresh blood and was not coagulating. The haemoglobin concentration of the first sample of fluid was $4.45 \mathrm{~g}$. $/ 100 \mathrm{ml}$. At subsequent aspirations the haemoglobin concentration became progressively lower (Fig. 4). No organisms, including acid-fast bacilli, were cultured from the fluid, and no abnormal cells were identified, normal blood cells only being found.

Immediate symptomatic relief occurred after aspiration of the pericardial effusion. The signs of cardiac tamponade disappeared and the heart size and shape returned to normal. When investigations were completed the patient was discharged well.

He has since been followed up as an outpatient and has shown no clinical or radiological evidence of further pericardial disease (Fig. 5).

\section{Discussion}

Purpuric manifestations are among the commonest physical findings in cases of Gaucher's disease. These result from a reduction of platelets as part of the pancytopenia associated

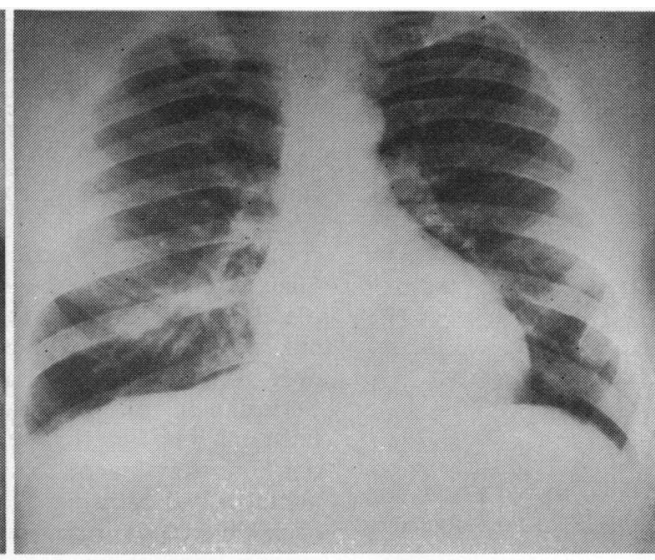

FI G. 5 
with hypersplenism. The basic fault appears to be megakaryocytic arrest rather than myelophthisis (Davis, Genecin, and Smith, 1949).

The usual manifestations of bleeding are petechiae, bruising, epistaxis, and occasionally gastro-intestinal bleeding. Only three other cases of bleeding into the pericardial sac have been described in Gaucher's disease which may be attributed to platelet deficiency. Brill et al. (1905) describe a patient who died of cardiac tamponade and at necropsy 2 litres of very bloody fluid were found in the pericardium. Altered red cells were the only cytological finding. Welt et al. (1929) record a patient who developed an enormous haemorrhagic pericardial effusion in whom they obtained a dramatic symptomatic result by aspirating $1,800 \mathrm{ml}$. bloody fluid from the pericardial sac. Roberts and Fredrickson (1967) describe a patient in whom aspiration of the pericardium before death yielded 150 $\mathrm{ml}$. blood. At necropsy $600 \mathrm{ml}$. blood was found in the pericardium, there being 'raging diffuse haemorrhagic pericarditis' present.

Haemorrhagic pericardial effusion has a variety of causes (Williams and Soutter, 1954; McKusick and Harvey, 1955; Wolff and Grunfeld, 1963). In a recent analysis of 105 cases of non-traumatic haemopericardium, Barbour, Hirst, and Johns (I96I) found that 60 per cent were associated with acute myocardial infarction (some of these patients were receiving anticoagulants), aneurysms of the aorta accounted for 33 per cent $(86 \%$ of these having dissecting aneurysms), 4 were due to metastatic carcinoma, and 3 to blood dyscrasias. Other causes include tuberculosis, rheumatic fever, uraemia, primary heart tumours, penetrating and non-penetrating chest injuries, post-operative, rheumatoid arthritis, disseminated lupus erythematosis, diagnostic procedures, and acute, benign, non-specific pericarditis.

Davis (1957) points out that pericardial effusions over $300 \mathrm{ml}$. in volume are likely to prove fatal. However, Barbour et al. (196I) suggest that gradual accumulations of blood in the pericardial sac are likely to permit longer survival. They comment that gradual accumulation of fluid is frequent in cases due to blood dyscrasias and coagulation defects.

Recent reviews of pericarditis all mention the occurrence of bloody pericardial effusions in blood dyscrasias, but only one of these (Wolff and Grunfeld, 1963) mentions Gaucher's disease as being associated with haemopericardium. The case they cite is, however, that of Rosenfeld and Epstein (196I), and is the patient who had malignant invasion of the pericardium from carcinoma of the bronchus.

The case reported here had previously had pulmonary tuberculosis, but there was no evidence clinically, radiologically, or on culture to suspect involvement of the pericardium in tuberculous disease. Antituberculous therapy was not given at this time, and there was no evidence of reaccumulation of pericardial fluid. While the significance of the raised titre for influenza $A$ virus in this case cannot be ignored, the clinical presentation, together with the volume and type of fluid aspirated, is not in favour of such an aetiology. Williams, Beckwith, and Wood (1960) and Connolly and Burchell (196I) point out that the three main aetiological factors to be considered in a subacute illness characterized mainly by pericarditis are: tuberculosis, neoplasm, and disseminated lupus erythematosis. No evidence for these was found, nor has any developed subsequently on prolonged followup, during which time the patient has remained well.

We should like to acknowledge the help of Dr. L. G. Davies, Consultant Cardiologist, Sully Hospital, and Dr. A. Bloom, Consultant Haematologist, Cardiff Royal Infirmary. The illustrations were prepared by the Department of Medical Illustration, Cardiff Royal Infirmary, and we should like to thank Mr. Ralph Marshall, Senior Lecturer in Medical Illustration, for these.

\section{References}

Barbour, B. H., Hirst, A. E., and Johns, V. J. (I96I). Nontraumatic hemopericarditis. An analysis of 105 cases. American fournal of Cardiology, 7, 102.

Benbassat, J., Bassan, H., Milwidsky, H., Sacks, M., and Groen, J. J. (1968). Constrictive pericarditis in Gaucher's disease. American fournal of Medicine, 44, 647 .

Brill, N. E., Mandlebaum, F. S., and Libman, E. (1905). Primary splenomegaly - Gaucher type. American fournal of the Medical Sciences, 129, 491.

Connolly, D. C., and Burchell, H. B. (I96I). Pericarditis: a ten year survey. American fournal of Cardiology, 7,7 .

Davis, F. W., Genecin, A., and Smith, E. W. (1949). Gaucher's disease with thrombocytopenia, an instance of selective hypersplenism. Bulletin of the fohns Hopkins Hospital, 84, 176.

Davis, H. A. (1957). Principles of Surgical Physiology. Cassell, London.

Gaucher, E. (1882). De l'Epithélioma Primitif de la Rate. Thesis. Octave Doin, Paris.

Hsia, D. Y., Naylor, J., and Bigler, J. A. (1959). Gaucher's disease. Report of two cases in father and son and review of the literature. New England Fournal of Medicine, 26I, 164 .

McKusick, V. A., and Harvey, A. M. (1955). Diseases of the pericardium. Advances in Internal Medicine, 7 , I57.

Reich, C., Seife, M., and Kessler, B. J. (I95I). Gaucher's disease: a review, and discussion of 20 cases. Medicine, 30, $\mathbf{~}$. 
Roberts, W. C., and Fredrickson, D. S. (1967). Gaucher's disease of lung causing severe pulmonary hypertension with associated acute recurrent pericarditis. Circulation, 35, 783.

Rosenfeld, S., and Epstein, S. (196I). Gaucher's disease complicated by metastatic carcinoma, presenting symptoms of recurrent pericardial tamponade with secondary acute renal failure. New York State fournal of Medicine, 6r (2), 4080.

Strickland, B. (1958). Skeletal manifestations of Gaucher's disease with some unusual findings. British Fournal of Radiology, 31, 246.

Welt, S., Rosenthal, N., and Oppenheimer, B. S. (1929). Gaucher's splenomegaly with especial reference to skeletal changes. Fournal of the American Medical Association, 92, 637.

Williams, C., and Soutter, L. (1954). Pericardial tamponade. Archives of Internal Medicine, 94, 57 I.

Williams, C. L., Beckwith, J. R., and Wood, J. E., Jr. (1960). Haemorrhagic pericardial fluid in acute, benign non-specific pericarditis: report of a case and review of the literature. Annals of Internal Medicine, 52, 914.

Wolff, L., and Grunfeld, O. (1963). Pericarditis. New England fournal of Medicine, 268, 419.

Zlotnick, A., and Groen, J. J. (196r). Observations on a patient with Gaucher's disease. American fournal of Medicine, 30, 637. 